\title{
Vocación y sentido: claves del valor educativo del arte
}

\section{Calling and meaning: keys of the educational value of art}

\section{Vocação e sentido: chaves do valor educativo da arte}

\author{
Javier Barraca Mairal* \\ Fecha de recepción: 15 de octubre de 2016 \\ Fecha de evaluación: 15 de marzo de 2017 \\ Fecha de aceptación: 8 de mayo de 2017 \\ Disponible en línea: 18 de mayo de 2017
}

DOI: http://dx.doi.org/10.18359/reds.2327

Cómo citar este artículo:

Barraca Mairal, J. (2017). Vocación y sentido: claves del valor educativo del arte. Revista Educación y Desarollo Social, 11(1), 172-186. DOI: org/10.18359/reds.2327

Doctor en Filosofía y Derecho, de la Universidad Complutense de Madrid; Profesor titular de Filosofía, de la Universidad Rey Juan Carlos, Madrid, España. Correo electrónico: javier.barraca@ urjc.es 


\section{Resumen}

Este artículo desarrolla la reflexión en torno a una clave del acercamiento humano a la obra de arte: la llamada al sentido de la vida. También busca extraer el valor educativo más hondo del arte. Para esto se estudia la relación del arte con la cuestión de la "vocación" personal, desde la perspectiva filosófica, y se recurre a los autores más significativos, a la reflexión en torno a la estética y a obras artísticas. Como resultado puede verse que la reflexión revela cómo esta cuestión resulta decisiva para vivir el valor educativo más hondo de las obras de arte. En la profunda llamada de que en toda obra maestra del arte puede encontrarse la clave de su valor educativo. La razón es que esa apelación abre a la persona a la cuestión del sentido de su propia vida y ayuda a ver la obra de arte como un mensaje personal. De esta manera, se concluye que para que el sujeto pueda tener una relación personal y creativa con la obra de arte debe poder conectarla con su propia vida y vocación. El arte ofrece así una fecunda luz a la hora de vivir la propia existencia con creatividad.

Palabras clave: arte, educación, ética, sentido, vocación, valores.

\section{Abstract}

This article develops the reflection around a key of the human approach to the work of art: the call to the meaning of life. It also seeks to extract the deepest educational value of art. For this, we study the relation of art to the question of personal "calling," from the philosophical perspective, and recourse is made to the most notable authors, to reflection on aesthetics and artistic works. As a result, it can be seen that reflection reveals how this issue is decisive for living the deepest educational value of works of art. In the deep call that in every masterpiece of art can be found the key to its educational value. The reason is that that appeal opens the person to the question of the meaning of their life and helps to see the work of art as a personal message. In this way, it is concluded that for the subject to have a personal and creative relationship with the work of art must be able to connect it with his life and vocation. Art thus offers a fruitful light when it comes to living one's existence with creativity.

Keywords: Arts, education, ethics, meaning, calling, values, sense.

\section{Resumo}

Este artigo desenvolve uma reflexão em torno a uma chave da aproximação humana para a obra de arte: a chamada para o sentido da vida. Também pretende extrair o valor educativo mais profundo da arte. Para isso se estuda a relação da arte com a questão da "vocação" pessoal, a partir da perspectiva filosófica, se recorre a os autores mais significativos, à reflexão em volta da estética e a obras artísticas. Como resultado, pode-se ver que a reflexão revela como esta questão é crucial para viver o valor educativo mais fundo das obras de arte. Na profunda chamada de que em toda obra-prima da arte pode encontrar-se a chave de seu valor educativo. A razão é que este apelo abre à pessoa para a questão do significado da sua própria vida e ajuda a ver a obra de arte como uma mensagem pessoal. Assim, conclui-se que para que o sujeito possa ter um relacionamento pessoal e criativo com a obra de arte deve ser capaz de se conectá-la com sua própria vida e vocação. A arte oferece assim uma luz fértil na hora de viver a própria existência com criatividade.

Palavras-chave: arte, educação, ética, sentido, vocação, valores. 


\section{Introducción. La dimensión educativa y ética del arte como una apelación personal de sentido}

Extraer el valor educativo y ético más rico de la obra de arte requiere que se dé en nosotros una determinada actitud. Con esto se hace referencia a aquella actitud que hace posible una fecunda vivencia de todo lo valioso: cierta "reverencia" no religiosa en su sentido convencional, sino en cuanto "respeto" hondo y atento del otro, actitud de fondo que nos permite en definitiva relacionarnos de forma personal. Esto es, al menos, lo que las investigaciones más hondas y fecundas han revelado, desde hace unos años, en torno a la experiencia estética y su valor formativo para lo ético, como el pensador A. López Quintás ha mostrado en sus certeros estudios a este respecto (2003).

La actitud de respeto profundo evidentemente se aleja de la desconfianza o el recelo, que con frecuencia han experimentado los seres humanos en relación con las imágenes, y que les ha llevado a juzgarlas, en ocasiones, como peligrosas o incluso dañinas para la felicidad y la ética (Besançon, 2003). Hemos de acercarnos, de acuerdo con lo que revela la propia experiencia estética y artística humana, a la obra de arte con sumo cuidado, con especial atención, y además "dialogar" con ella; 174 solo así esta alcanza a cobrar todo su vigor humanístico, formativo e incluso ético en nosotros. Debemos, en fin, hablar con ella, escucharla y responder por dentro. ${ }^{1}$

Gracias a un fértil encuentro con la obra de Arte podemos conocernos mejor a nosotros mismos e incluso vincularnos, con su ayuda, a otros, hasta unirnos fecundamente con ellos, urdir tramas de interacción, entrar en relación, formar comunidad. Hay encuentros con obras de arte y experiencias estéticas, en efecto, que han cambiado la vida de personas, como han glosado los innumerables testimonios de los artistas de todos los tiempos (Keats, Byron, Wilde, Stendhal, Tolstoi, Dostoievsky, Unamuno, Kavafis, etc.) También, la relación con ciertos modos de hacer artísticos ha colaborado históricamente con un modo decisivo al encuentro interpersonal y social, e incluso a la configuración de las identidades de pueblos, naciones y culturas, como testimonian el arte funerario egipcio, la escultura greco-romana, la arquitectura de los templos románicos y góticos, el estilo pictórico renacentista, la música barroca y clásica, la literatura del Romanticismo, etc.

Si nuestro acercamiento logra ser adecuado, si acertamos a vivirlo como una "apelación personal" una vocación, una fuente de sentido, la obra de arte hará que se transfigure este encuentro

No ha de extrañarnos, entonces, que de la literatura contemporánea en lengua española podamos extraer un rico magisterio en torno a este "leer", con fruto, la imagen artística. Por ejemplo, Borges, Sábato, Mújica Láinez, Unamuno, Ayala, García Márquez, etc. 
y se convertirá, de algún modo, en palabra significativa que nos habla de nosotros, sin dejar de ser ella misma. Se transformará en puente para un diálogo fecundo, en puerta para la reflexión personal, en una ventana hacia los más grandes valores.

\section{Sobre el carácter cultural y universal del arte}

Como sabemos, todas las sociedades humanas generan expresiones o manifestaciones artísticas, sean estas de uno u otro tipo. Estas responden a la peculiar forma de ser y a la cultura concreta que poseen las diversas sociedades o comunidades humanas que las engendran. El arte forma parte, en efecto, de la cultura de todo pueblo o sociedad humanos, como la historia de la estética ha venido mostrando (Bayer, 1965). Así, por ejemplo, existe arte tanto en Occidente como en Oriente, y tanto en la prehistoria como en la edad antigua, media, moderna o contemporánea. Pero también es verdad que el arte del extremo oriente presenta unas características diversas a las del arte europeo o americano, o que el arte del románico no es igual al del gótico, ni al del Renacimiento, etc. Tampoco es igual la forma de trabajar y crear de los artistas en un lugar o momento o en otro. De esta manera, en la película El tormento y el éxtasis de Carol Reed (1965) se describen las admirables y especiales peripecias del trabajo artístico de Miguel Ángel y de su tiempo, la relación concreta con sus mecenas, su técnica y su vida, etc.
El papel del arte es decisivo como factor de comunicación o expresión de las personas; además, constituye un modo de integración en una sociedad o cultura determinada. Esto quiere decir que conocer y vivir el arte de una sociedad o comunidad ayuda a integrarse en esa sociedad y cultura. Vivir una cultura comporta vivir también su arte y sus manifestaciones o claves estéticas; esto hasta el punto que incluso en las instituciones, organizaciones y empresas o equipos de trabajo existe un clima estético, una cultura de las formas sensibles que resulta importante conocer a la hora de integrarse en ellas (Barraca, 2015).

Aunque cada cultura y sociedad generan su propio arte, uno característico o peculiar, en el arte de altura se da una dimensión universal y duradera; es decir, las obras maestras del arte pueden conectar con lo más profundo del ser humano, sea este de una cultura $\mathrm{u}$ otra y así haya transcurrido poco o mucho tiempo. Por ejemplo, podemos visitar el Museo del Louvre en París y contemplar allí obras de lugares lejanos y épocas distantes, prácticamente de todos los continentes, pero que logran emocionarnos e impresionarnos. El arte puede conmover a personas de muy diferentes sociedades y tiempos, pues despierta y llama a algo permanentemente presente de alguna manera en todos los seres humanos. Podemos captar los valores estéticos de determinado arte aun cuando provengan de culturas y sociedades distintas de la nuestra, pues responden a claves que 
existen en lo más hondo de nuestra naturaleza humana.

Esta "universalidad" del arte, compatible con su carácter cultural, conecta con la honda cuestión de los transcendentales del ser, que ofrece un fundamento metafísico para ello. En especial, se ha reflexionado acerca del valor de la belleza y su profundo vínculo con el ser. El ser, lo uno, lo verdadero y lo bello, de alguna forma, en su último alcance, confluyen en su raíz (Lobato, 2005).

El hondo vínculo registrable entre el arte y la naturaleza humana ha hecho que se haya juzgado a este como signo de humanidad e incluso que se haya reflexionado acerca de la relación entre los diversos valores estéticos y artísticos en especial, la belleza y el ser, en su sentido transcendental o más hondo, como hemos visto. Así, al arte y a la experiencia estética profunda se los ha considerado como señal propia de la peculiar participación en el ser y la existencia vivida por los humanos, como un rasgo característico de la dignidad personal. De aquí arrancan los análisis críticos acerca de determinadas derivaciones socioculturales del arte, como la conocida obra de J. Ortega y Gasset, La deshumanización del arte y otros ensayos de estética (1966). Todo esto, hasta el punto de que los estudiosos acostumbran a buscar objetos artísticos, adornos y otros signos estéticos, cuando investigan si unos restos primitivos determinados corresponden o no a algún asentamiento o individuo humano, y cuando en- cuentran manifestaciones artísticas lo entienden como un posible indicio de que tales restos correspondieron a un grupo o sujeto humano. Por ejemplo, incluso entre los más ancestrales o remotos pobladores de la península ibérica, se han hallado testimonios elocuentes y magníficos de arte, como las pinturas de la cueva de Altamira, y en América, por ejemplo, se han localizado impresionantes, hermosas y elocuentes máscaras, de muy diferente tipo y función, dotadas de una antigüedad singular.

\section{El arte como fruto de la creatividad humana}

El arte constituye un fruto de la existencia de la sensibilidad estética humana y, a la par, de nuestra "creatividad" (López Quintás, 1987). Esta clase de creatividad se expresa en las formas más variadas y fecundas, a través de medios o materiales muy diversos; por ejemplo, gracias a la imagen, el sonido o el movimiento. Dicha rica creatividad se concreta en obras de muy diferente tipo, como las de la literatura, la pintura, la música, la escultura, la arquitectura, el cine, la danza, etc., así como en estilos artísticos muy distintos entre sí, como el barroco, el neoclasicismo o el impresionismo.

Al mismo tiempo, la enorme riqueza y diversidad de la creatividad artística, que se acaba de sintetizar, al desarrollarse revela que existen muy diferentes valores estéticos, relacionados con lo artístico. Desde luego, lo bello ocupa en el arte un lugar decisivo; pero lo bello no es 
el único valor estético ni artístico. Hay obras de arte que no son exactamente bellas, pero que se consideran arte. Pensemos en "El grito" de Munch, o en las gárgolas de la catedral de Notre Dame de París, etc. Así, las realizaciones artísticas pueden participar de muy diversos valores estéticos o formales, como la citada creatividad, pero también de la originalidad, la expresividad, la elegancia, la gracia, etc. Ahora bien, deben en cualquier caso participar de un modo notable en algún tipo de valor sensible o estético, para llegar a ser juzgadas como artísticas.

Sin duda, en presencia de los valores estéticos de lo bello, pero asimismo de lo estético en general (de lo elegante, lo original, lo grácil, lo sublime...), nuestro ánimo se eleva, se levanta por encima de lo vulgar o prosaico y de lo burdo. De esta manera, el ser humano parece ascender desde lo simplemente material a algo superior, gracias a su sensibilidad estérica. De aquí que se afirme que las experiencias estéticas y artísticas nos elevan, nos hacen conectar con el nivel o dimensión de lo más alto, lo más cuidado o delicado, lo mejor (Consejo Pontificio para la Cultura, 2006).

Con todo esto, enlazan las descripciones actuales de la estética y del arte, que los relacionan o vinculan con el fecundo espíritu de "lo lúdico" (del juego) a través de lo creativo. En efecto, en la estética y en el arte hay una cierta dosis de "juego", un deseo o anhelo de olvidar nuestro afán u ocupación rutinarios, como si se abriera con ellos una pausa en lo inmediato y urgente; un tiempo de "contemplación", un goce en la propia actividad más allá de sus utilidades exteriores. Este impulso lúdico o de juego y creatividad debe ser apreciado y valorado, pues sin duda siempre es preludio o anuncio de nuestra capacidad para cuidar la forma de las cosas, superarnos y esforzarnos con gozo por lo hermoso y valioso. Esto también debe aplicarse al mundo del trabajo, de modo que la creatividad, el desinterés y el juego humanos se encuentren presentes también en nuestras tareas o labores.

\section{Lo subjetivo y lo objetivo en el arte}

Aunque la creatividad artística es personal, por cuanto quienes engendran lo artístico son personas, cabe descubrir puntos en común entre los distintos autores y obras. Así, se habla de estilos artísticos, de escuelas e incluso de épocas enteras del arte, dentro de la variedad y singularidad de cada artista y realización concretos. La creatividad artística, por tanto, no implica el desconocimiento o el desprecio de la tradición ni de las realizaciones de otros.

Lo precedente implica que en el arte y en lo estético se da tanto lo subjetivo o lo que tiene que ver con los sujetos o personas como lo objetivo lo referente a las obras y procesos o métodos. Por eso, se habla de lo subjetivo y de lo objetivo en el arte (Blanco, 2007). En efecto, las personas y las sociedades o grupos culturales se relacionan con las 
obras artísticas o las experiencias estéticas, tanto las suscitadas por otros como por ellas mismas, siempre de un modo singular, personal. Esto, puesto que cada cual "interpreta" desde su subjetividad, desde su propio ser personal la obra y la experiencia, aunque lo vivamos dentro de un marco compartido con otros, y con referencias o valores comunes. Toda obra artística dice o habla de manera diversa, de acuerdo con sus diferentes interlocutores, es decir, según sea uno u otro su espectador, su receptor, su auditorio, etc., aunque también exista siempre alguna comunidad o punto compartido en esto.

En ocasiones, se incurre en el fácil tópico lo en la creencia repetida de que sobre gustos no hay nada escrito, y que en concreto el gusto estético es totalmente libre, pues lo que le parece bello a alguien puede no serlo para otro. Sin embargo, en el arte y en lo estético no todo es absoluta o completamente subjetivo, porque aunque cada cual puede tener sus preferencias individuales y captar más o menos un valor estético, valorar o apreciar mejor o peor una obra de arte, siempre existen también algunos elementos compartibles y algunos criterios objetivos o no arbitrarios para el juicio estético y artístico. Cuando alguien está bien formado, en su sensibilidad estética y artística, sabe distinguir mejor la presencia de los valores estéticos en 178 las obras o realidades, pues ha afinado entonces su juicio y sensibilidad, y tiene un criterio más maduro o certero. Así, es capaz de descubrir los valores estéticos estén donde estén, se expresen de un modo o de otro, y vivirlos de manera más adecuada o profunda. Por ejemplo, a alguien pueden gustarle más o menos "Las meninas" de Velázquez, la Acrópolis y el Partenón de Atenas, el teatro de Shakespeare, El Quijote de Cervantes o La Odisea de Homero, pero si tiene una sensibilidad y formación estéticas básicas, mínimamente desarrolladas, reconocerá que en estas obras existen al menos ciertos valores artísticos. En realidad, toda gran obra de Arte y experiencia estética nos enseñan algo hondo sobre el hombre, sobre la cultura y sobre nosotros mismos, si sabemos apreciarlas adecuadamente.

\section{El arte y la formación ética: claves metodológicas}

Todas las sociedades y culturas han aprovechado el poder de evocación y de expresión artísticos a fin de influir en sus conciudadanos, y en especial su enorme capacidad formativa. Las comunidades de las más diversas épocas y latitudes han recurrido al arte para transmitir sus más estimados valores de una a otra generación. El arte supone un extraordinario cauce de comunicación. A este respecto, existen ya fecundos estudios sobre la literatura como cauce de formación ético. En concreto, el drama o teatro se ha considerado un ámbito privilegiado a este propósito. Platón y Aristóteles propusieron la tragedia griega como ejemplo de ello, a pesar de sus reticencias en relación con la comedia. Esto aparece con claridad en el caso de 
Platón en su República (2005) y en el de Aristóteles en su Poética (1974).

López-Quintás (1993), entre otros pedagogos contemporáneos, se ha distinguido al mostrar la necesidad, a este respecto, de seguir un método adecuado, fundado en la creatividad, para explotar el inmenso poder formativo de la literatura y de las restantes bellas artes. El cine, asimismo, se viene utilizando como un hondo medio de formación en valores, quizás aún de un modo incipiente y con ciertas vacilaciones, aunque a la par con una enorme fecundidad práctica (Almacellas, 2004). De igual forma, se han dado interesantes análisis, desde antiguo, en torno al campo de la música, la arquitectura, la escultura o la danza. Ahora bien, ¿cuáles son las claves fundamentales, las pautas más importantes, a la hora de aprovechar educativamente el arte, desde la dimensión ética de la persona? ¿Qué principios generales han de tenerse presentes para ello?

López Quintás (1987) ha elaborado una síntesis original a este respecto. De acuerdo con él, las claves de método, en este terreno, son las siguientes:

1) Discernir, gracias a las obras artísticas, "los procesos" auténticos del desarrollo moral: no limitarse a evaluar meros actos o conductas aisladas. Por ejemplo, no fijar tanto la atención en si una conducta resulta o no moralmente adecuada en una obra, sino en el singular camino por donde transita el personaje dentro de esta.
2) Acercarse a las obras artísticas de un modo "personal". No reproducir simplemente los criterios ajenos y exteriores, en relación con ellas. Procurar ponerse en el lugar de quienes las protagonizan. Ahora bien, este esfuerzo por comprender o empatizar con "el otro" se halla, desde antiguo, en la base misma de todo lo ético.

3) Utilizar para esto un procedimiento genético o "vital", en el que la experiencia o vivencia, la recreación interior, jueguen un papel crucial; vivir "por dentro" estos procesos, no superficial o epidérmicamente, comprenderlos de un modo profundo. En síntesis, con una honda creatividad. Por ejemplo, interrogarse por qué alguien escoge uno $u$ otro curso vital, buscando las causas profundas de ello, y aprender a anticipar las consecuencias éticas que eso puede acarrear, y ver así la relación profunda que todo esto puede guardar con mi propia vida.

\section{Temporalidad y obra de arte}

El arte, en cuanto obra humana, constituye una realidad que acontece en el tiempo, al igual que su autor, el ser humano; de aquí, el tenor histórico y evolutivo que acompaña siempre a lo artístico. Sin embargo, a la vez, la obra artística, de algún modo, transfigura el instante, pues hay en ella algo intemporal, por cuanto resulta perenne en su valor, eterna, capaz de recorrer todas las 
épocas y de revelar su valor más allá de su propio momento de gestación.

Para operar esta perdurabilidad, el arte se dice que "cristaliza", adensa, concentra el instante. Esto lo hace, sin embargo, fecundándolo, como la luz en un caleidoscopio; es decir, lo fija sin despojarlo de vida o dinamismo interno; por el contrario, transformándolo en un cauce vivo de belleza y valor incesantes. Debido a esto, resulta posible mostrar por su intermedio todo un proceso humano, un desarrollo vital, que comporta instantes diversos, etapas sucesivas ligadas entre sí. Por supuesto, la imagen artística logrará esto mejor cuanto más habitada esté de genialidad. Baste recordar aquí obras como "El Guernica", de Picasso, o "El ángelus", de Millet, o películas como Ciudadano Kane, de Wells (1946), Casablanca, de Curtiz (1946) o La reina de África, de Huston (1952), en las que se refleja la multiplicidad del instante en su evolución constante: en ellas casi puede verse el tiempo en su propio movimiento, que transporta a los sujetos y es transportado de algún modo también por estos. En efecto, vivir es moverse o ser movido hacia algún indefinible lugar, con toda la connotación moral, de amor y de desamor, que ello comporta.

Tanto por su propia creatividad, como por su capacidad de conjugar e incorporar elementos diversos, la obra visual resulta fecunda. Hay pinturas, por 180 ejemplo, que manifiestan los procesos humanos no solo por su "encarnación" pictórica del instante decisivo, sino también por determinados recursos artísticos como la escenografía, el detalle, el marco, el símbolo, la articulación de escenas, incluso la glosa, la palabra, el lema, etc. Pensemos en los sugerentes cuadros del barroco Valdés Leal, acerca del tiempo o la muerte, o en la museística actual, la escultura contemporánea, las performances, etc. La ópera supone, a este respecto, uno de los hitos señeros en la integración significativa de los aspectos artísticos, acaso solo superado por el teatro y el cine. El "eco", la influencia, la capacidad de resonancia en el interior del sujeto convierten estas manifestaciones en verdaderos campos de prueba del desarrollo moral. Algunas imágenes e instantes dramáticos y operísticos han quedado grabados, en la conciencia histórica, como símbolos de arduas luchas en pro de los valores (desde la célebre tragedia griega, al propio teatro del absurdo, pasando por las obras de Verdi o los esfuerzos en este sentido de algunas representaciones contemporáneas).

\section{Arte y maduración personal}

El arte puede y debe colaborar a la maduración de sus destinatarios, a causa de que ofrece una oportunidad para vivir un encuentro con valores muy singulares, valores que coadyuvan a este proceso de crecimiento de los sujetos. Autores clásicos en esto, como Read (1977), y ya antes que él Schiller (1963), han reflexionado acerca de este carácter educativo del arte y su vínculo con el desarrollo personal. Así, se da una estrecha relación entre los procesos 
existenciales la vida y el Arte, gracias a la libertad y la personalidad propias del sujeto. En términos contemporáneos, gracias a su "singularidad" personal. $\mathrm{El}$ arte va fraguando en carácter dentro de sus destinatarios; los procesos que propone pueden ser incorporados por la persona, de un modo insubstituible, inimitable, distinto. Nada más lógico, desde el momento cuando todas las personas se sitúan ante las imágenes o realidades estéticas, siempre, de una forma inconfundiblemente singular, única (en la medida en que se abren desde dentro de sí a ellas, realmente). Esto, por cuanto cada cual es susceptible de "interpretar" desde una subjetividad distinta la obra y experiencia artísticas, aún en un marco de referencias comunes indispensable. La obra dice o habla de manera diversa, de acuerdo con sus diferentes interlocutores, salvada una cierta comunidad de lenguaje. Esta interlocución es así "acción", movimiento y diálogo únicos que desencadenan el propio crecimiento ético del sujeto.

Además, toda imagen artística se contempla de una forma "vital", en el sentido "existencial"; es decir, "vivimos" la obra al contemplarla, la hacemos nuestra, la interiorizamos dentro de nuestro propio curso vital. Lo contemplado se transforma en vida nuestra, en experiencia vivida y sabiduría personal. Se incorpora, así, al patrimonio de nuestra memoria e identidad. Se hace parte de "nosotros" mismos, y se funde con nuestro mismo ser o "carácter ético". Porque a la postre ni el acto ni el proceso moral guardan la clave ética fundamental, sino la persona concreta, el sujeto de la libertad hecha vida.

Este vivir nuestras experiencias estéticas hasta integrarlas en nuestra identidad reclama el hecho de que las "interpretemos". Interpretar con fruto supone para el ser humano comprender algo, pero, a la par, hacerlo en una clave personal, que pone en juego, como Gadamer (1977) ha mostrado, una hermenéutica integral. En ella, tienen un relevante papel nuestros valores y principios, nuestra tradición, historia y memoria, nuestra comunidad de vida e interpretación, nuestras costumbres y contexto, etc. Todo esto interviene, también, a la hora de vivir el encuentro del sujeto con la obra de arte.

Un cuadro o una película pueden mostrar, en suma, todo un proceso humano en su vertiente ética. Además, deben ayudarnos a vivirlo de modo personal y vital, a experimentarlo y enriquecernos con él. Respecto a esto, imaginemos, por ejemplo, la "Anunciación" de Fray Angélico, custodiada en el Museo del Prado. Asistimos aquí, sin duda, a un "acontecimiento", no a un mero momento separado en el tiempo. Se trata no de un hecho aislado, sino de la culminación de un proceso, y el comienzo de otro de particular relevancia. Encarna una historia. Para el intérprete creyente, se trata a la vez de un punto de llegada y de arranque en la larga historia de las relaciones entre Dios y el hombre. En concreto, la clave de este proceso de relación se halla en el valor de "la 
humildad", que se ve singularmente reflejado en la estampa, gracias a un orden armonioso presente entre sus múltiples elementos. El cuadro narra cómo el bien y la felicidad sobrevienen, desde lo alto, al hombre, a través de la humildad. Así, la actitud recíproca del ángel y de la Virgen revela que está teniendo lugar algo muy especial, que no va a detenerse en sí mismo, sino a fructificar. El marco del hecho nos ayuda, también, a situarnos de forma adecuada, a centrarnos en lo importante. Los colores y la dulzura de la escena nos enseñan el carácter transcendental del instante, su dinamismo. La luz, abierta y difundida en toda su amplitud, hasta los menores rincones, nos ayuda a conectar con los valores de universalidad y plenitud del suceso, con su extraordinario poder de expansión. En general, todo en la obra nos comunica el profundo sentido humano de lo contemplado.

\section{Arte y "vocación"}

Para que el arte nos eduque en los ricos valores que encarna, hemos de vivir antes la experiencia estética con intensidad y fruto. Ahora bien, esto reclama el que aprendamos a ver y leer lo artístico, a contemplarlo e interpretarlo de un modo verdaderamente hondo. Ello implica que alcancemos a conectarlo con nuestra vocación más profunda, con el sentido original de nuestra propia y personal

182 existencia. Así, aunque ciertamente es el tenor histórico, temporal, "procesual" y caracteriológico, que se refleja en la obra, lo que logra educarnos éticamente, esto sucede solo cuando sabemos captarlo en su alcance personal o existencial. De manera que, de cierta forma, los valores transmitidos permanecerán en el exterior de nuestro progreso moral, hasta que no logremos vincularlos a nuestro propio proceso de desarrollo personal, en un grado singular, irrepetible, único.

Para esto último, resulta en efecto crucial la vocación; nuestra propia e inconfundible vocación (Barraca, 2003). Aquí, vocación indica la llamada personal a dar sentido a la propia vida; el sendero o camino irrepetible de nuestro deambular vital. Pues bien, solo si captamos el lazo entre el proceso de la obra y nuestro proceso personal, nuestra vocación, logra alcanza el primero a formarnos de un modo profundo, de alcance ético.

La vocación mencionada entronca obviamente con la cuestión del sentido de la propia vida. En esto, se han basado los aportes de Frankl (2001) acerca de la logoterapia, por ejemplo. Según este, vivir humanamente reclama desarrollar nuestra propia vida con sentido, en cierto modo vocacionalmente. De aquí que la clave de la vocación, expresada o concretada en nuestro ideal o proyecto de vida, se haya convertido en la actualidad en un eje pedagógico fundamental, al que la educación no puede renunciar. De manera que educar y autoeducarnos solo es posible desde el conocimiento de nuestro propia originalidad personal, como expone la fecunda pedagogía de J. Kentenich (2005), por ejemplo. Así, aclarar por parte de cada sujeto qué metas dinamizadoras o ideales, qué valores 
y alianzas o vínculos profundos van a articular e impulsar la vida constituye una tarea irrenunciable, central para todo lo educativo (Strada, 2007). Además, los símbolos sensibles, estéticos o artísticos pueden ayudarnos en dicha labor de una manera notable, dado que colaboran a autoconocernos al identificarnos con sus mensajes (Carmona, 2004).

De esta amnera, nuestra vocación e ideal en suma orientan nuestra existencia hacia el sentido, el cual ilumina el camino de la vida y nos alienta a la hora de recorrer un sendero con frecuencia poblado por sufrimiento, no solo por gozo. Ahora bien, las obras de arte, manantiales de creatividad y de reflexión, pueden ayudarnos a descubrir ese sentido, en la medida en que logramos captar su vínculo con nuestra vocación y con nuestra propia originalidad.

\section{Análisis a partir de casos, experiencias y ejemplos}

Un ejemplo singular de la clase de experiencia profunda, propiciada por el encuentro con una obra de arte y que se viene analizando en este artículo, puede hallarse en el libro contemporáneo $\mathrm{El}$ regreso del hijo pródigo (Nouwen, 2005). En este, el autor relata su propia biografía a partir de su relación con este cuadro concreto y desarrolla todo su texto por medio del significado que el homónimo cuadro de Rembrandt va cobrando en su propia trayectoria vital. Ese genial tratado de Nouwen nos enseña cómo un cuadro, interpretado desde la clave de la vocación y el sentido personales, puede ayudarnos a profundizar éticamente, de un especialísimo modo, en toda nuestra existencia y enseñarnos acerca de nosotros mismos y de nuestra relación con "los otros" (como decía Lévinas).

Lo precedente, desde la hondura de lo filosófico, se debe en el fondo a esa "alteridad" al otro, presente en toda relación e incluso en el mismo corazón de mi identidad o de mi propio yo. Ahora bien, este diálogo entre el yo y el tú, entre la identidad y la alteridad también se da en el interior mismo, y de manera especial en la obra de arte. Esta relación entre el otro y el mismo, entre nosotros y los demás, de hecho, adquiere una pujanza peculiar en el arte, dadas su intensidad significativa y su universalidad, pues este desvela al ser humano lo humano mismo, su misma humanidad. Aquí, la consideración de la fecunda filosofía de la alteridad de Lévinas, expresada por ejemplo en su conocida obra Totalidad e Infinito (1977), puede contribuir enormemente a comprender, interpretar y vivir con alcance estas experiencias. Este pensador ha glosado en esta clave honda de sentido y apelación personal su propia experiencia en relación con algunas de las obras de Dostoievsky u otros literatos, hasta descubrir en ellas una profunda inspiración para su singular pensamiento, el cual está orientado hacia una responsabilidad irremplazable por el otro hombre.

También debemos recordar que todo lenguaje, y el arte constituye un lenguaje, refiere a un "sentido" o significado 
profundo. Incluso cabe afirmar que la vida humana misma, para ser vivida con fruto, reclama esa búsqueda u orientación hacia el sentido, como estableció Frankl en su fecunda "logoterapia".

En realidad, toda gran imagen artística nos enseña algo sobre el hombre y la ética y, por tanto, sobre nosotros mismos, al cabo. Así, por ejemplo, en el caso del autor de este artículo, la citada Anunciación de Fray Angélico fue el primer cuadro del Museo del Prado contemplado con verdadero estupor, en la temprana juventud. El primero que logró retener largo tiempo en su observación al contemplador. El primero que ayudó de verdad a preguntar e intuir cómo lo reflejado allí podría contagiar algo de su luz y belleza a la propia existencia. Fue, en síntesis, la primera puerta, con forma de obra maestra de la pintura, que se abrió, y que abrió a su contemplador, luminoso y con una profundidad de perspectiva todavía hoy inolvidable, el sendero de la propia vocación.

Sin embargo, se trató tan solo del primer gran asombro. Por eso, esto mismo podría predicarlo cualquier lector que admire lo artístico acerca de otras muchas experiencias personales las suyas, las de cada cual de contemplación artística, suscitadas ya por obras antiguas o contemporáneas. En torno a estas últimas, para muchos, la exposición de Dalí en Montmartre, en los años noventa, se ha

184 transformado en el signo de toda una etapa de ilusa irrealidad, frustrada al cabo, en una juventud que el tiempo desengaña. Aquel jardín de sueños su- rrealistas cobró luego, en la conciencia de sus espectadores y visitantes, su auténtica dimensión de profético alarido visual de inundación de lo imaginario y emotivo. He aquí el poder fantástico de la obra del arte, cuando nos apela de modo personal, hasta fundirlo todo, como lo onírico, en vida, en nuestra propia vida.

Numerosas experiencias prácticas, que se han desarrollado dentro y fuera de los ámbitos académicos, testimonian esto muy claramente. Así, en el entorno educativo el axiólogo Méndez ha utilizado en España imágenes de célebres obras de arte para la formación en valores, gracias a la tecnología, mostrando diversas obras maestras e interrogando luego a los alumnos acerca de los valores reflejados o presentes en estas. ${ }^{2}$

En el caso del contexto universitario, nuestra experiencia indica que importante tener en cuenta cuando los estudiantes leen de forma personal desde la apelación personal las obras de arte que analizan, ellos mismos logran descubrir todo un rico mundo de valores éticos de modo natural en ellas. Se emocionan, lloran o se entusiasman al notar la luz que el arte ofrece sobre su existencia personal. La obra habla acerca de su propia vida y de su sentido, y esto les abre a valores que implican responsabilidad

$2 \quad$ Cf. el proyecto y materiales elaborados por el equipo de investigación de Estudios de Axiología para el Ministerio de Educación, cultura y Deporte, de España, titulados Vivir la ética. Puede verse en http://contenidos. educarex.es/cnice/etica/enlaces.htm. 
y un compromiso profundo consigo mismos y con los demás.

\section{Conclusiones}

Este artículo ha ahondado en el gran valor educativo y ético que puede y debe alcanzar, para el sujeto humano, la vivencia de la experiencia del encuentro con la obra de arte. En particular, se ha estudiado cómo para extraer y vivir los valores formativos y éticos de esta experiencia debe establecerse con ella una relación significativa y fecunda, en la que la reflexión resulta crucial. Esta relación se funda en el carácter a la par cultural y universal de lo artístico, en su naturaleza a la vez subjetiva y objetiva, y en la peculiar fecundidad de la creatividad humana y de los ricos valores a los que está vinculada.

Para ello, el sujeto ha de interpretar este encuentro estético, a la luz del significado de esta vivencia para su propia felicidad y búsqueda de sentido. El sujeto tiene que conectar, entonces su experiencia estética con su propia y personal vocación, con su singular itinerario vital. Además, ha de reflexionar en torno a qué puede enseñarle o aportarle a él en persona la relación con la obra, qué sentido profundo se ilumina y abre para él, a través de este encuentro con la realidad artística concreta.

Gracias a su vocación de sentido, por tanto, todo ser humano puede vivir su relación con la obra de arte de una forma radicalmente personal, llena de valores.
El Arte nos proporciona una hermosa luz para comprender nuestra propia vida, y nos enseña a vivirla con una honda creatividad. Algunos pensadores que han investigado acerca de esto, y que se han citado a este propósito, son López Quintás, Gadamer, Nouwen, Lévinas, Frankl o Kentenich. También se han referido algunas experiencias prácticas, fundadas en las precedentes apreciaciones teóricas o reflexivas, en la medida en que se ha juzgado que estas colaboran a iluminar y a avanzar en la profundización en este camino.

\section{Referencias}

Almacellas, M. A. (2004). Educar con el cine. Pamplona: Eiunsa.

Aristóteles (1974). Poética, Madrid: Gredos. Barraca, J., (2003). Vocación y persona. Madrid: Unión Editorial.

Barraca, J. (enero-junio, 2015). La necesidad de coherencia entre la ética y la estética en las organizaciones. Katharsis, (19), 249-264.

Bayer, R. (1965). Historia de la estética, México, D. F: Fondo de Cultura Económica.

Blanco, P. (2007). Estética de bolsillo (2da. Ed.). Madrid: Palabra.

Besançon, M. (2003). La imagen prohibida. Madrid: Biblioteca de Ensayo, Siruela.

Carmona, G. (2004). Mi proyecto de vida. Córdoba: Nueva Patris.

Consejo Pontificio para la Cultura (2006). La via pulchritudinis. Roma: Vaticano.

Frankl, V. (2001). El hombre en busca de sentido (2lava. Ed.). Barcelona: Herder. 
Gadamer, H. G. (1977). Verdad y método. Salamanca: Sígueme.

Kentenich, J. (2005). Textos pedagógicos. Santiago: Nueva Patris.

Lévinas, E. (1977). Totalidad e Infinito. Salamanca: Sígueme.

Lobato, A. (2005). Ser y belleza. Madrid: Unión.

López Quintás, A. (1987), Estética de la creatividad. Barcelona: Promociones y Publicaciones Universitarias [PPU].

López Quintás, A. (1993). El arte de pensar con rigor y vivir de forma creativa. Madrid: Asociación para el Estudio de las Ciencias Humanas y Sociales.

López Quintás, A. (2005). Descubrir la grandeza de la vida. Verbo Divino, Estella, Navarra.
Nouwen, H. (2005). El regreso del hijo pródigo. Madrid: Promociones y Publicaciones Universitarias [PPU].

Ortega y Gasset, J. (1966). La deshumanización del arte y otros ensayos de estética. Madrid: Revista de Occidente en Alianza Editorial.

Platón (200). República. Madrid: Alianza.

Read, H. (1977). Educación por el arte. Buenos Aires: Paidós.

Schiller, A. (1963). Cartas sobre la educación estética del hombre (Trad. V. Romano). Madrid: Aguilar.

Strada, A. (2007). Propuesta pedagógica. Córdoba: Nueva Patris. 